\title{
TERMINATION AND DOMINANCE OF CORONARY ARTERIES: ON
} TELANGANA POPULATION

\author{
Bheemesh Pusala ${ }^{* 1}$, M. Venkateshwer Reddy ${ }^{2}$.
}

${ }^{* 1}$ Tutor, Department of Anatomy, ESIC Medical College,Sanathnagar,Hyderabad Telangana, India.

${ }^{2}$ Associate Professor, Department of Anatomy, SVS Medical College, Mahaboobnagar, Telangana, India.

\section{ABSTRACT}

Introduction: Coronary arteries supply oxygen rich blood to entire heart muscle, Arterial supply to heart is achieved by two arteries, which are the only branches from ascending aorta. These arteries branch in such a manner that they occupy atrioventricular and interventricular groove in the shape of a crown. Hence they are called the coronary arteries. The artery supplying the Posterior Descending artery (PDA) determines the coronary dominance. the right dominant coronary circulation is one in which the PDA is a terminal branch of Right Coronary Artery (RCA) and in left dominance, PDA arises from left coronary artery Left dominant hearts are at an increased risk of coronary heart diseases. The present survey was therefore conducted to find out the variations in termination and dominance of coronary arteries.

Materials and Methods: The material for the present study comprises of adult human heart collected from the cadavers from the dissection hall of anatomy department of S.V.S medical college, Mahabubnagar from 2007 to 2016. The hearts of 80 adult cadavers fixed with $10 \%$ formaldehyde, With the help of Scalpel, Forceps, Scissors, we used Dissection method to secure the heart specimen, then $\mathrm{KOH}$ method used To separate the heart muscle mass and for highlight the arterial system Fevicryl crimson red colour .For the Angiogram study, 20 Coronary angiograms and 20 CT angiograms films were collected from the Department of Cardiology, Yashoda hospital, Secunderabad to compare the coronary arteries in the living with that cadavers.

Results: Right coronary artery terminated as a $7.5 \%$ before right border, $15 \%$ at right border, $22.50 \%$ before Crux and $55 \%$ at crux or beyond crux. Left coronary artery terminated as a $15 \%$ at Apex, $85 \%$ Lower 1 Brd of Posterior IV groove.and Right Coronary Artery Dominance were found in $70 \%$ hearts, Left Dominance were found in $15 \%$ hearts and balanced were found in $15 \%$ hearts.

Conclusions: Better anatomical knowledge about the dominance of coronary artery and its variation is essential for cardiologists and interpretation of coronary angiograms by radiologist.

KEY WORDS: Right Coronary Artery (RCA), Left Coronary Artery (LCA), Posterior Descending Artery (PDA), Dominence.

Address for Correspondence: Dr. Bheemesh Pusala, H.No-4/2/704, Indranagr colony, Vikarabad, RangaReddy Dist Telangana, India. Pin-501101 Mob. No.: +919642630764,+917075326427

E-Mail: bheemesh.india@gmail.com

\section{Access this Article online}

\begin{tabular}{c|c} 
Quick Response code & Web site: International Journal of Anatomy and Research \\
ISSN 2321-4287 \\
www.ijmhr.org/ijar.htm
\end{tabular}

Received: 25 Feb 2017

Peer Review: 27 Feb 2017

DOI: 10.16965/ijar.2017.161
Revised: None
Accepted: 03 Apr 2017

Published (O): 30 Apr 2017

Published (P): 30 Apr 2017

\section{INTRODUCTION}

Cardia is from the Greek word Kardia, meaning heart. It is the heart that provides the motive force acting as a pump to move blood through the circulatory system. Heart receives its blood supply from the coronary vessels. It may seem like the heart has easy access to blood, however the blood passing through the chambers of 
heart does not actually supply it, instead special blood vessels, called coronary arteries deliver blood into heart muscle itself.

The word coronary is derived from the Latin word co-ro-ne, Greek ko ro ne, means anything hooked or curved and coronary means 'encircling in a manner of crown' [1].

Arterial supply to heart is achieved by two arteries, which are the only branches from ascending aorta. These arteries branch in such a manner that they occupy atrioventricular and interventricular groove in the shape of a crown. Hence they are called the coronary arteries [2].

Coronary arteries are the largest vasa vasorum of the heart, the heart develops from the fusion of two primitive endothelial tubes, which represent the ventral aorta. The right coronary artery arises from the right coronary sinus (anterior aortic sinus) of the ascending aorta and the left coronary artery arises from the left posterior aortic sinus of the ascending aorta [3]. Ostia of the coronary arteries are located in the center of the corresponding aortic sinuses. Malformations of the position of the ostia and origin of coronary arteries lead to high risk of sudden death [4].

Vascular anomalies pose a great challenge to anatomists and Cardio-Thoracic surgeons. Knowledge of normal coronary anatomy and its variations or anomalies is essential in heart surgeries. Failure in detection of these anomalies leads to complications [5].

Holsted, a pioneer American surgeon has said that the best way to avoid injury to blood vessels is to know all possible variations in course, distribution and branches. Any surgical trauma sustained by blood vessels is irreparable leading to the necrosis of the part involved.

The coronary arteries, studied for many years to determine the pathophysiology of coronary artery disease, have been under intense scrutiny by those attempting to revascularize areas of ischemic myocardium using grafts to bypass arteries that have become obstructed by atheroma [6].

Major or minor congenital anomalies of the coronary arteries are present in those undergoing cardiac catheterization. Depending upon the origin, course, and termination of the anoma- lous vessel, certain coronary anomalies may be associated with sudden death, syncope, other congenital heart diseases, or angina syndromes, or they may be incidental findings, without adverse prognosis. Accurate recognition and documentation of coronary artery anomalies at the time of coronary angiography are essential to determine the significance of such findings and to avoid therapeutic complications [7].

Global population has different types of coronary predominance and having different degree of myocardial infarction and different percentage of incidence. The myocardial infarction is seen usually due to the obstruction of left coronary artery because it is having more transverse diameter than right. The degree of severity of myocardial infarction is more if it is left coronary dominant [8].

This current study is done to throw light upon the termination of right coronary artery and left anterior descending, branches of left coronary artery. This is to help the cardiologists for a better approach to cardiac disease for a precise cure.

\section{MATERIALS AND METHODS}

The material for the present study comprises of adult human heart collected from the cadavers from the dissection hall of anatomy department of S.V.S medical college, Mahabubnagar from 2007 to 2016. The hearts of 80 adult cadavers fixed with $10 \%$ formaldehyde, With the help of Scalpel, Forceps, Scissors,

I used Dissection method To secure the heart specimen, then $\mathrm{KOH}$ method used To separate the heart muscle mass and for highlight the arterial system Fevicryl crimson red colour .For the Angiogram study 20 Coronary angiograms and 20 CT angiograms films were collected from the Department of Cardiology, Yashoda hospital Secunderabad to compare the coronary arteries in the living with that cadavers

\section{RESULTS}

Level of Termination of Right Coronary Artery: Observation on the level of termination of right coronary artery revealed that it terminated at crux or beyond crux in 66 out of 120 (55\%) specimens, before crux in 27 (22.5\%) specimens, 
at right border of heart in $18(15 \%)$ specimens and before right border in $9(7.5 \%)$ specimens.

Table 1: Showing the Level of Termination of Right Coronary Artery.

\begin{tabular}{|c|c|c|}
\hline RCA termination level & $\begin{array}{c}\text { No. of } \\
\text { specimens }\end{array}$ & Percentage \\
\hline Before right border & 9 & 7.5 \\
\hline At right border & 18 & 15 \\
\hline Before crux & 27 & 22.5 \\
\hline At crux or beyond crux & 66 & 55 \\
\hline
\end{tabular}

LEVEL OF RCA TERMINATION

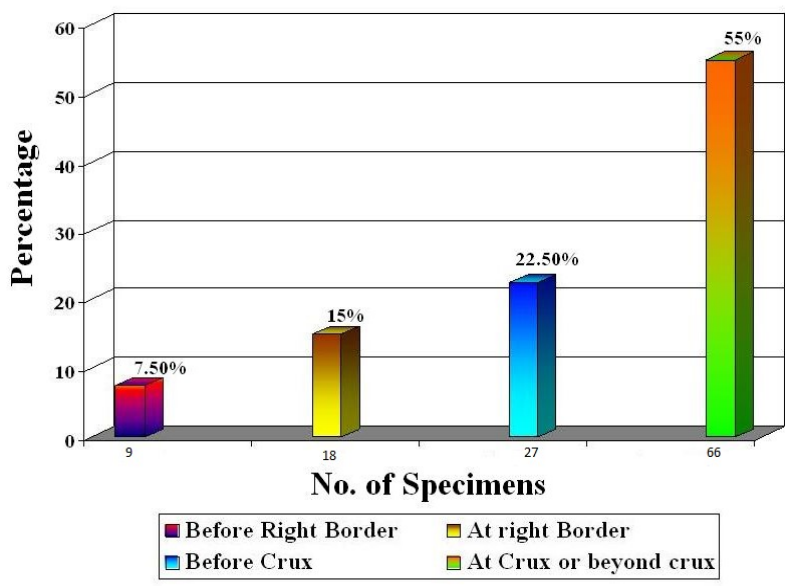

Level of termination of left anterior descending artery: Observation on the level of termination of LAD branch of left coronary artery revealed that it terminated beyond apex in the lower part of the posterior IV groove in 102 out of 120 specimens (85\%), and at the apex in 18 out of 120 specimens (15\%).

Table 2: Showing the Level of termination of left anterior descending artery:

\begin{tabular}{|c|c|c|}
\hline $\begin{array}{c}\text { LADA termination } \\
\text { level }\end{array}$ & $\begin{array}{c}\text { No. of } \\
\text { specimens }\end{array}$ & Percentage \\
\hline At apex & 18 & $15 \%$ \\
\hline $\begin{array}{c}\text { Lower 1/3rd of } \\
\text { posterior IV groove }\end{array}$ & 102 & $85 \%$ \\
\hline
\end{tabular}

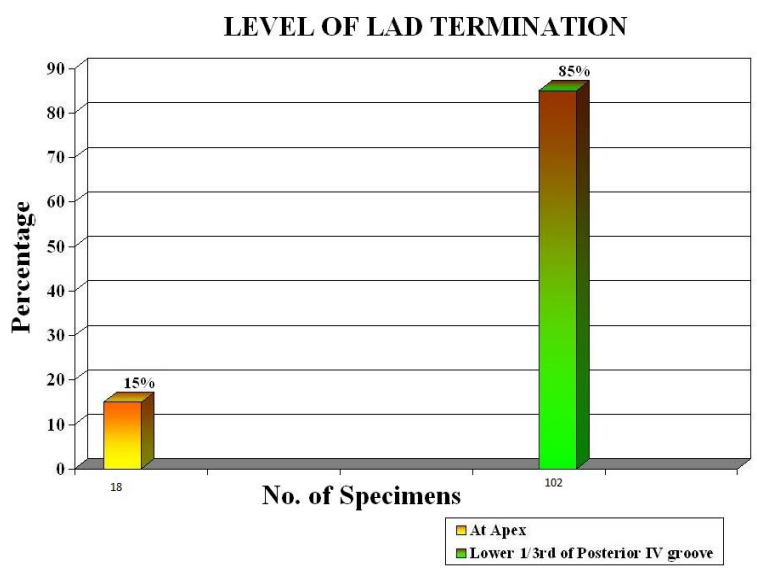

Origin of posterior descending artery: Observations on the origin of the PDA to note the 'predominance' of heart revealed that 84 out of 120 specimens $(70 \%)$ were branches from RCA and 18 out of 120 specimens (15\%) were branches from LCA. In the remaining 18 hearts (15\%) posterior IV groove received separate branches from both the arteries.

Table 3: Showing the origin of posterior descending artery.

\begin{tabular}{|c|c|c|}
\hline $\begin{array}{c}\text { Posterior descending } \\
\text { artery }\end{array}$ & Number & $\%$ \\
\hline Right coronary artery & 84 & $70 \%$ \\
\hline Left coronary artery & 18 & $15 \%$ \\
\hline Both & 18 & $15 \%$ \\
\hline
\end{tabular}

Coronary artery dominance: Observations on the dominance of heart revealed that 84 out of 120 specimens (70\%) were right dominant, 18 out of 120 specimens $(15 \%)$ were left dominant and the 18 (15\%) were having balanced circulation.

Table 4: Showing the Coronary artery dominance.

\begin{tabular}{|c|c|c|}
\hline $\begin{array}{c}\text { Coronary Artery } \\
\text { Dominance }\end{array}$ & $\begin{array}{c}\text { No. of } \\
\text { Specimens }\end{array}$ & Percentage (\%) \\
\hline Right dominance & 36 & 70 \\
\hline Left dominance & 7 & 15 \\
\hline Balanced & 7 & 15 \\
\hline
\end{tabular}

CORONARY ARTERY DOMINANCE

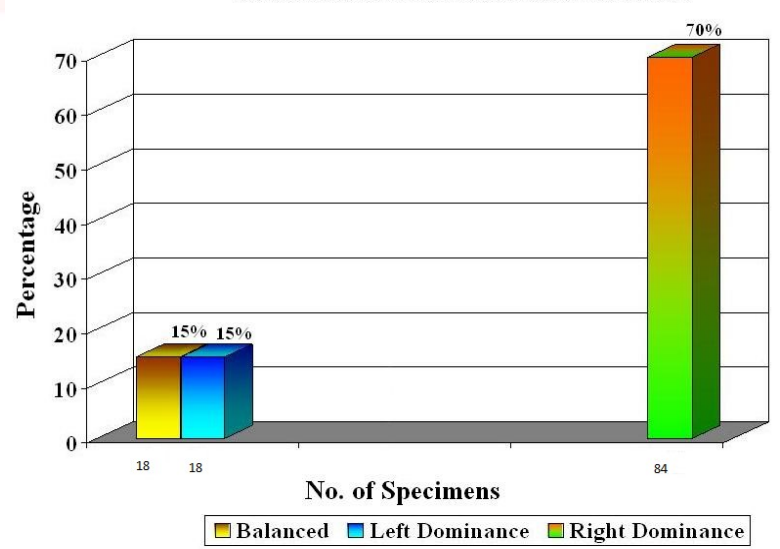

Coronary Artery Dominance

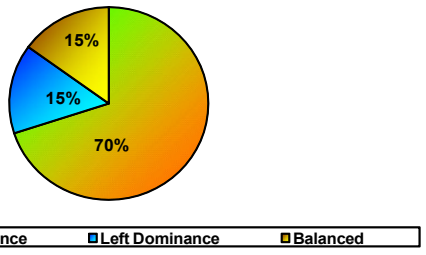


Bheemesh Pusala, M. Venkateshwer Reddy. TERMINATION AND DOMINANCE OF CORONARY ARTERIES: ON TELANGANA POPULATION.

Fig. 1: Specimen no. 9 showing normal coronary arteries in (a) anterior view and (b) posterior view.
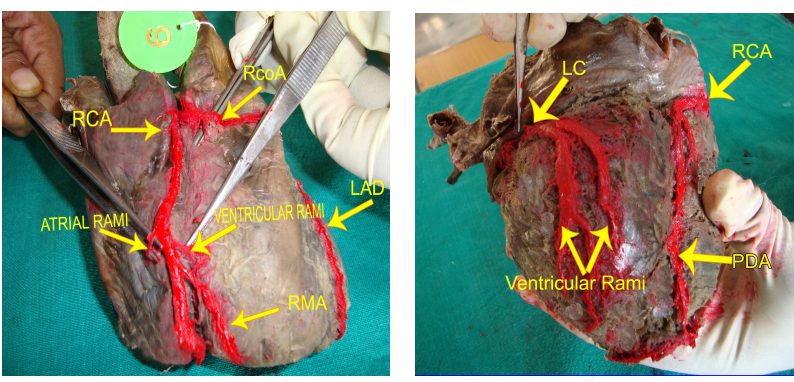

Fig. 2: Specimen no. 4 showing 3 PDA arises from RCA.

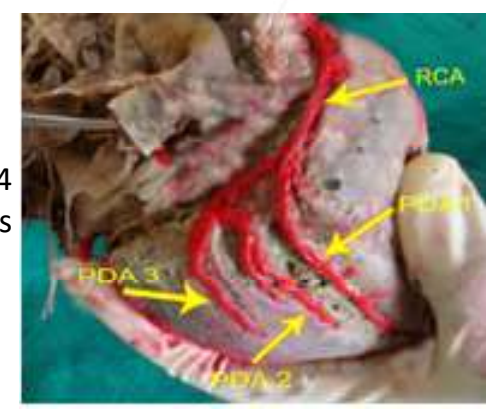

Fig. 3: Specimen no. 13 showing LCAMT Trifurcation.

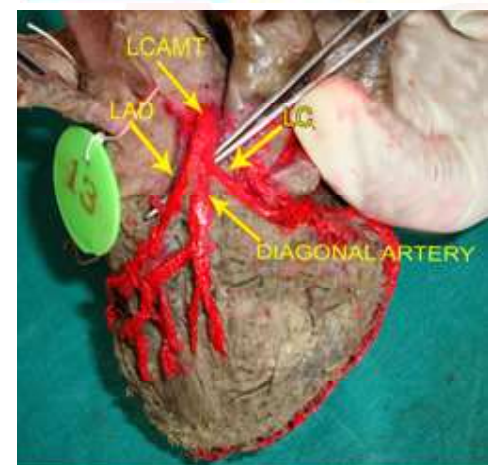

Fig. 4: Specimen No 92, Showing (a)RCA Total Block,(b)LCA continues as PDA.

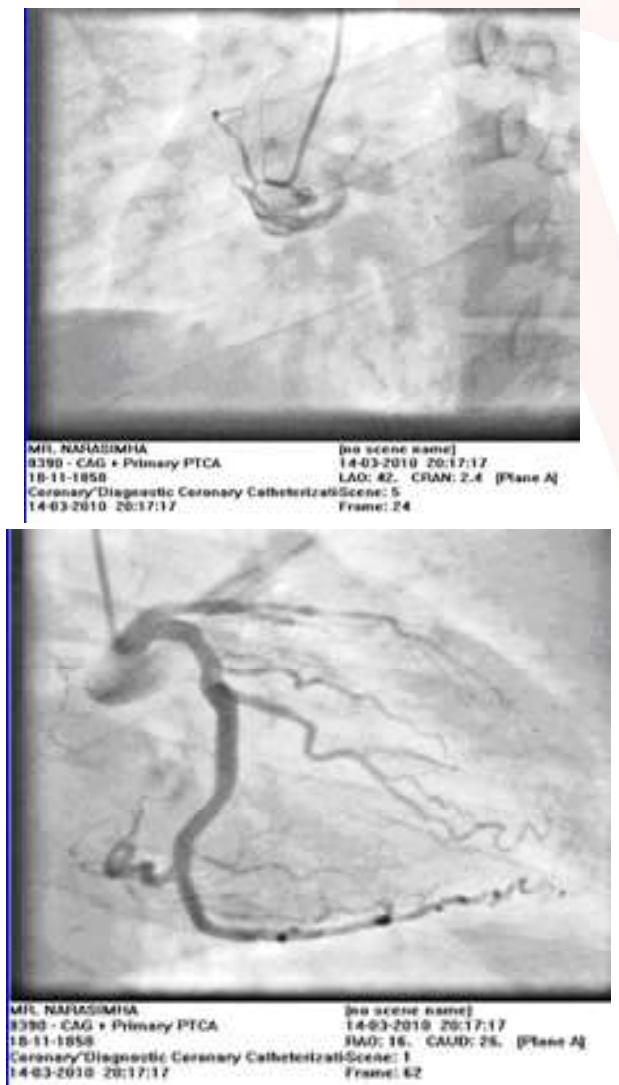

Fig. 5: Specimen No 17, Showing (a)RCA with large IV branch, (b) LCA with Trifurcation.
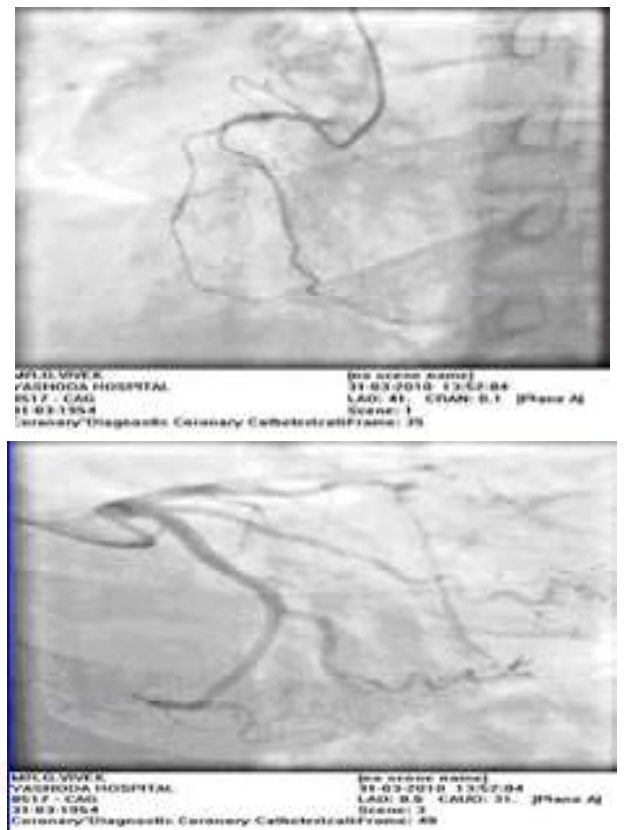

Fig. 6: Specimen No 95, Showing (a) LC proximal segment, (b) large PDA arising from LC.
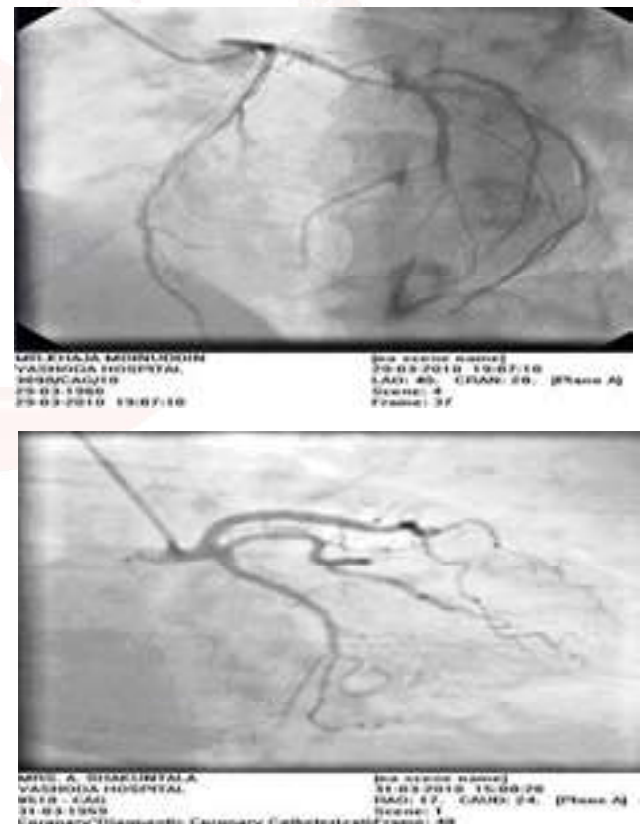

Fig. 7: Specimen No.105 showing (a) Anterior view(b ) Posterior view.

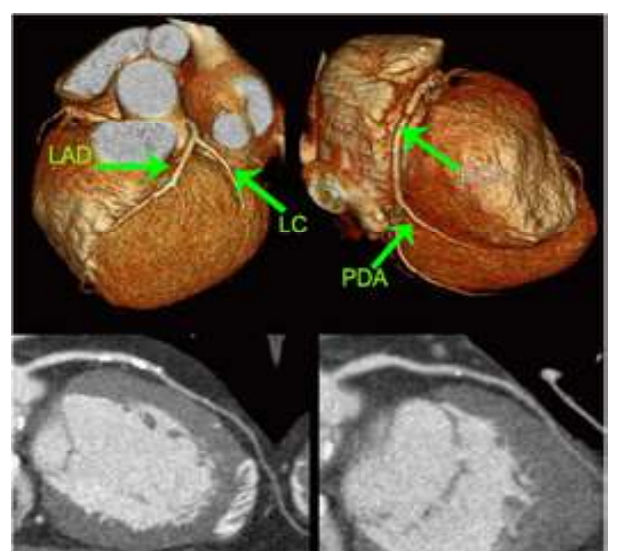


Fig. 8: Showing the specimen No.108 with RCA, LCA.

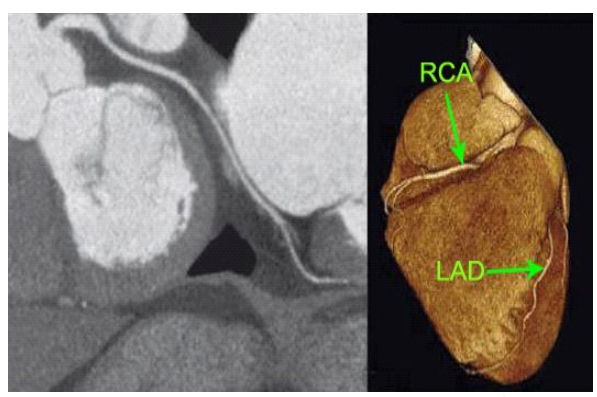

\section{DISCUSSION}

The branching pattern and distribution of coronary arteries have been studied by various workers in the past. Coronary artery disease is one of the most common causes of death due to changing dietary habits, sedentary habits, smoking etc, in developing countries like India. With the advancement of medical technology, the incidence of coronary angiography and coronary bypass surgeries, stunt, balloon angioplasty is also increasing. The present study was taken up with the hope that the data collected in the study may help clinician to interpret properly the findings which will lead on to its remedy.

In this study, a note on the dominance of the heart, the termination of RCA and LAD branch was done.

Level of termination of right coronary artery: In the present study RCA terminated at crux or beyond crux in 55\%, before crux in $22.5 \%$ and right border in $15 \%$ and It is terminated before right border $7.5 \%$. Is correlating with the grays at the right border $10 \%$, before the crux $20 \%$, At the crux or beyond crux $60 \%$ [9]. Kalpana. $R$ (2003) The right coronary artery terminated at 1 to $3 \mathrm{cms}$ beyond crux in $76 \%$, reached upto the lef border in $8 \%$, terminated at the crux in $6 \%$, at right margin in $7 \%$ and between right margin and crux in $3 \%$ of the specimens [10]. In this RCA termination at crux or beyond crux $(76+8$ +6) $90 \%$ and before crux 3\% and at right border $7 \%$ is not correlating with the present study.

Table 5: Level of termination of right coronary artery.

\begin{tabular}{|c|c|c|c|c|}
\hline SI.No. & Study done by & $\begin{array}{c}\text { At the right } \\
\text { border (\%) }\end{array}$ & $\begin{array}{c}\text { Before the } \\
\text { crux (\%) }\end{array}$ & $\begin{array}{c}\text { At the crux or } \\
\text { beyond crux (\%) }\end{array}$ \\
\hline 1 & Grays 38th Edition [9] & 10 & 20 & 60 \\
\hline 2 & Kalpana. R (2003) [10] & $7 \%$ & $3 \%$ & $90(76+8+6)$ \\
\hline 3 & Present study & 15 & 22.5 & 55 \\
\hline
\end{tabular}

Int J Anat Res 2017, 5(2.1):3735-40. ISSN 2321-4287
Level of termination of left anterior descending: In the present study the LAD terminated beyond apex in the lower $1 / 3$ of the posterior IV groove in $85 \%$ and at the apex in $15 \%$ is correlating with the kalpana.R (2003) at apex $12 \%$, Lower $1 / 3$ rd posterior interventicular groove $80 \%$ (10) but not with study of JAMES (1961) At apex $23 \%$, Lower $1 / 3$ rd posterior interventicular groove $60 \%$ [11].

Table 6: Showing the Level of termination of left anterior descending.

\begin{tabular}{|c|c|c|c|c|}
\hline SI.No. & Study done by & $\begin{array}{c}\text { Before apex } \\
(\%)\end{array}$ & $\begin{array}{c}\text { At apex } \\
(\%)\end{array}$ & $\begin{array}{c}\text { Lower 1/3rd posterior } \\
\text { interventicular groove (\%) }\end{array}$ \\
\hline 1 & James (1961)[11] & 17 & 23 & 60 \\
\hline 2 & Kalpana. R(2003) [10] & 8 & 12 & 80 \\
\hline 3 & Present study & - & 15 & 85 \\
\hline
\end{tabular}

Coronary dominance: - In the present study $70 \%$ were Right Dominant and $15 \%$ were Left Dominant and $15 \%$ showed Balanced circulation is correlating with Sally P All work (1987) Right Dominance 70\%, Left Dominance 15\%, Balanced 15\% [2] and K.V. Venkatesh (2005) Right Dominance $68.75 \%$, Left Dominance $16.66 \%$, Balanced $14.58 \%$ [8].

Table 7: Showing the coronary dominance.

\begin{tabular}{|c|l|c|c|c|}
\hline SI.No. & \multicolumn{1}{|c|}{ Study done by } & $\begin{array}{c}\text { Right Dominance } \\
(\%)\end{array}$ & $\begin{array}{c}\text { Left Dominance } \\
(\%)\end{array}$ & $\begin{array}{c}\text { Balanced } \\
(\%)\end{array}$ \\
\hline 1 & Cavalcanti (1995)[12] & 88.18 & 11.82 & - \\
\hline 2 & Kalpana R (2003) [10] & 89 & 11 & - \\
\hline 3 & B.K. Omer (1977) [13] & 53.3 & 16.7 & 30 \\
\hline 4 & Gutelins and Sabiston (1961) [14] & 46.9 & 21.9 & 13.2 \\
\hline 6 & K.V.Venkateshu (2005)[8] & 68.75 & 16.66 & 14.58 \\
\hline 7 & Banchi (1903)[15] & 17 & 10 & 73 \\
\hline 8 & Schlesinger (1940)[16] & 48 & 34 & 18 \\
\hline 9 & Sally P Allwork (1987)[2] & 70 & 15 & 15 \\
\hline 10 & Present study & 70 & 15 & 15 \\
\hline
\end{tabular}

\section{CONCLUSION}

The present study on level of termination of right coronary artery showed that 55\% terminated at crux or beyond. The level of termination indicates that right coronary artery supplies major part of right atrium, right ventricle and the length of right coronary artery in the antriove ntricular groove beyond the crux will show the blood supply to the left ventricle adjacent to the posterior interventricualr groove, the posterior $1 / 3 r d$ of the interventricular septum hence the conducting system, 
The present study on the predominance of heart shows $70 \%$ were right dominant, $15 \%$ were balanced and $15 \%$ were left dominant. The degree of severity of myocardial inarction is more if it is left coronary artery dominance. Better anatomical knowledge about the dominance of coronary artery and its variation is essential for cardiologists and interpretation of coronary angiograms by radiologist.

\section{Conflicts of Interests: None}

\section{REFERENCES}

[1]. Co-ro-ne. Dorland's illustrated medical dictionary. 30th edt, Philadelphia:Saunders, 2000:420.

[2]. Allwork SP. The applied anatomy of the arterial blood supply to the heart in man. Anat Soci Great Britian and Ireland Aug 1987;153:1-16.

[3]. Data AK. Essentials of human anatomy. Thorax and abdomen. 3rd Ed., Calcutta, Current Books International. 1994;80-86.

[4]. Frescura C, Basso C, Thiene G, Corrado D, Pennelli T, Angelini A, Daliento L. Anomalous origin of coronary arteries and risk of sudden death: a study based on an autopsy population of congenital heart disease. Hum. Pathol. 1998;29:689-695.

[5]. Vikram Palimar. Origin of right coronary artery from the left sinus of Valsalva. International Journal of Anatomical Variations 2008;1:12-13.

[6]. Walmsley R, Watson H, Kirklin JW. Clinical anatomy of the heart. Edinburgh: Churchill Livingstone. 1978:199-214.
[7]. Charles E. Wilkins et al "Coronary Artery Anomalies" A Review of More than 10,000 Patients from The Clayton Cardiovascular Laboratories" Texas Heart Institute Journal 1988;15:166-173.

[8]. Venkateshu KV. Coronary artery dominance. Anat Karnataka Jun 2005;2:1:18-21.

[9]. Grays 38th edition corona artery dominance 2012.

[10]. Kalpana R. A study of principal branches of coronary arteries in human. J Anat Soc. India Dec 2003;52:2:137-140.

[11]. James, T.N. : Anatomy of the coronary arteries. 1st edition ; Hoeber Med Div, Harper \& Row : New York. (1961).

[12]. Cavalcanti JS, de Lucena Oliveira M, Pais e Melo AV Jr, Balaban G, de Andrade Oliveira CL, de Lucena Oliveira E. Anatomic variations of the coronary arteries. Arq Bres Cardiology. 1995;65(6):489-492.

[13]. Omar BK. Coronary artery predominance - A new parameter for its study. J Anat Soci Ind 1977;26:2:8590.

[14]. Vasko, J.S., Gutelius, J. and Sabiston Jr., D.C. A Study of Predominance of Human Coronary Arteries Determined by Arteriographic and Perfusion Technics. The American Journal of Cardiology, 1961;8:379384. http://dx.doi.org/10.1016/0002-9149(61) 9015 7-6.

[15]. Banchi A. Le variazioni delle. "arteriae coronariae cordis" e la morfologia di questi vasi. Lo Sperimentale.1903;57:367-369.

[16]. Schlesinger MJ. Relation of anatomic pattern to pathologic conditions of the coronary arteries. Arch Path. 1940;30:403-415.

How to cite this article:

Bheemesh Pusala, M. Venkateshwer Reddy. TERMINATION AND DOMINANCE OF CORONARY ARTERIES: ON TELANGANA POPULATION. Int J Anat Res 2017;5(2.1):3735-3740. DOI: 10.16965/ijar.2017.161 